\title{
A vibrational spectroscopic study of the silicate mineral ardennite-(As)
}

\author{
Ray L. Frost ${ }^{\mathrm{a}, *}$, Andrés López ${ }^{\mathrm{a}}$, Yunfei Xi ${ }^{\mathrm{a}}$, Ricardo Scholz ${ }^{\mathrm{b}}$, Antonio Luciano Gandini ${ }^{\mathrm{b}}$

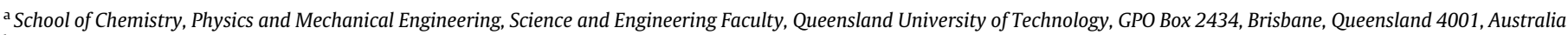 \\ ${ }^{b}$ Geology Department, School of Mines, Federal University of Ouro Preto, Campus Morro do Cruzeiro, Ouro Preto, MG 35,400-00, Brazil
}

\section{H I G H L I G H T S}

-We have studied the mineral ardennite-(As).

- Qualitative chemical analysis shows a homogeneous phase, composed by $\mathrm{Si}$, $\mathrm{Mn}, \mathrm{Al}$ and As.

- Raman bands at 3041, 3149, 3211 and $3298 \mathrm{~cm}^{-1}$ are attributed to the stretching vibrations of water

- Bands attributable to $\mathrm{OH}$ units were found.

- Water adsorbed on the surfaces of mineral ardennite-(As) was identified.

\section{A R T I C L E I N F O}

\section{Article history:}

Received 13 August 2013

Received in revised form 10 September 2013

Accepted 29 September 2013

Available online 8 October 2013

\section{Keywords:}

Silicate

Raman spectroscopy

Ardennite-(As)

Infrared spectroscopy

Adsorbed water
G R A P H I C A L A B S T R A C T

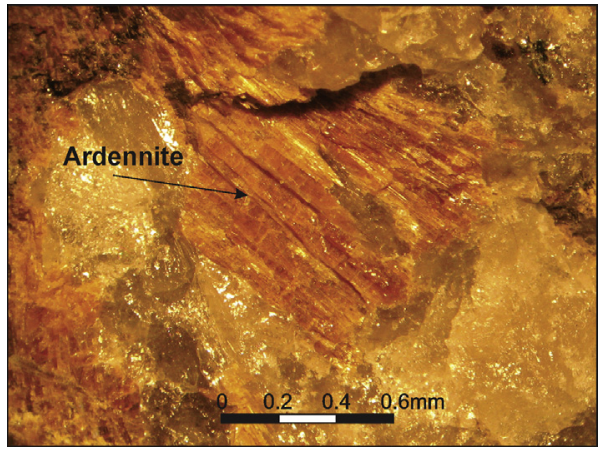

\begin{abstract}
A B S T R A C T
We have used a combination of scanning electron microscopy with EDX and vibrational spectroscopy to study the mineral ardennite-(As). The mineral ardennite-(As) of accepted formula $\mathrm{Mn}_{4}^{2+}(\mathrm{Al}, \mathrm{Mg})_{6}\left(\mathrm{Si}_{3} \mathrm{O}_{10}\right)$ $\left(\mathrm{SiO}_{4}\right)_{2}\left(\mathrm{AsO}_{4}, \mathrm{VO}_{4}\right)(\mathrm{OH})_{6}$ is a silicate mineral which may contain arsenate and/or vanadates anions. Because of the oxyanions present, the mineral lends itself to analysis by Raman and infrared spectroscopy. Qualitative chemical analysis shows a homogeneous phase, composed by $\mathrm{Si}, \mathrm{Mn}, \mathrm{Al}$ and As. Ca and $\mathrm{V}$ were also observed in partial substitution for Mn and As. Raman bands at 1197, 1225, 1287 and $1394 \mathrm{~cm}^{-1}$ are assigned to SiO stretching vibrations. The strong Raman bands at 779 and $877 \mathrm{~cm}^{-1}$ are assigned to the $\mathrm{AsO}_{4}^{3-}$ antisymmetric and symmetric stretching vibrations.

The Raman band at $352 \mathrm{~cm}^{-1}$ is assigned to the $v_{2}$ symmetric bending vibration. The series of Raman bands between 414 and $471 \mathrm{~cm}^{-1}$ are assigned to the $v_{4}$ out of plane bending modes of the $\mathrm{AsO}_{4}^{3-}$ units. Intense Raman bands observed at 301 and $314 \mathrm{~cm}^{-1}$ are attributed to the $\mathrm{MnO}$ stretching and bending vibrations. Raman bands at $3041,3149,3211$ and $3298 \mathrm{~cm}^{-1}$ are attributed to the stretching vibrations of $\mathrm{OH}$ units. There is vibrational spectroscopic evidence for the presence of water adsorbed on the ardennite-(As) surfaces.
\end{abstract}

(c) 2013 Elsevier B.V. All rights reserved.

\section{Introduction}

The mineral ardennite-(As) of formula $\mathrm{Mn}_{4}^{2+}(\mathrm{Al}, \mathrm{Mg})_{6}\left(\mathrm{Si}_{3} \mathrm{O}_{10}\right)$ $\left(\mathrm{SiO}_{4}\right)_{2}\left(\mathrm{AsO}_{4}, \mathrm{VO}_{4}\right)(\mathrm{OH})_{6}$ is a silicate mineral which may contain arsenate and/or vanadates anions [1]. This mineral originally was referred to as ardennite, which was named for the type locality in the Ardennes Mountains in Belgium; it has since been redefined

\footnotetext{
* Corresponding author. Tel.: +61 73138 2407; fax: +61 731381804 .

E-mail address: r.frost@qut.edu.au (R.L. Frost).
}

as ardennite-(As), as there is also a vanadate $\left(\mathrm{VO}_{4}\right)$ analogue of the mineral [1]. The two minerals form a continuous solid solution. Ardennite-(As) is a rare mineral that occurs in pegmatites, quartz veins, and highly oxidized manganese and aluminum rich sediments [2-5].

The mineral is orthorhombic [6-8] of point group: $2 / \mathrm{m} 2 / \mathrm{m} 2 / \mathrm{m}$ and space group: Pnmm: $a=8.7126(8), \quad b=18.5124(11)$, $c=5.8108(8)$, and $Z=2$. According to Donnay and Allman [9], the crystal structure of ardennite-(As) can be derived from that of epidote by Ito-type twinning; it leads to the $\mathrm{Si}_{3} \mathrm{O}_{10}$ groups, which 
strengthen the bond chains along $c$. As in epidote, chains of octahedra sharing edges extend along $b$. These chains are connected by the $\mathrm{SiO}_{4}$ and $\mathrm{Si}_{3} \mathrm{O}_{10}$ groups. $(\mathrm{As}, \mathrm{V}) \mathrm{O}_{4}$ tetrahedra do not share corners with $\mathrm{SiO}_{4}$ tetrahedra [9].

There is an apparent lack of information on the vibrational spectra of ardennite-(As). The reason for such a lack of information is not known; yet the mineral contains $\mathrm{OH}$ units, siloxane units and arsenate and/or vanadates units. Such units lend themselves to vibrational spectroscopy. Raman spectroscopy has proven most useful for the study of mineral structures especially at the molecular level. The objective of this research is to report the Raman and infrared spectra of ardennite-(As) and to relate the spectra to the mineral structure.

\section{Experimental}

\section{Samples description and preparation}

The ardennite-(As) sample studied in this work occurs as single crystals with tabular habitus up to $1 \mathrm{~cm}$ in association with quartz. The sample is from the Salmchâteau, Vielsalm, Stavelot Massif, Luxembourg Province, Belgium, the type locality for the mineral [1]. Ardennite-(As) occurs in association with quartz. The mineral shows yellow color and vitreous to sub-adamantine luster. An image of ardennite-(As) is provided in the Supplementary information 1 .

The mineral has been analyzed by X-ray diffraction. The XRD pattern of our ardennite-(As) matches the standard exactly. The XRD pattern of our ardennite-(As) is given in the Supplementary information.

The sample is part of the collection of the Geology Department of the Federal University of Ouro Preto, Minas Gerais, Brazil, with sample code SAC-088. The sample was gently crushed and the associated minerals were removed under a stereomicroscope Leica MZ4. The ardennite-(As) sample studied in this work was analyzed by scanning electron microscopy (SEM) in the EDS mode to support the mineral characterization.

\section{Scanning electron microscopy (SEM)}

Experiments and analyzes involving electron microscopy were performed in the Center of Microscopy of the Universidade Federal de Minas Gerais, Belo Horizonte, Minas Gerais, Brazil (http://www. microscopia.ufmg.br). Ardennite-(As) crystals were coated with a $5 \mathrm{~nm}$ layer of evaporated carbon. Secondary Electron and Backscattering Electron images were obtained using a JEOL JSM-6360LV equipment. Qualitative and semi-quantitative chemical analyzes in the EDS mode were performed with a ThermoNORAN spectrometer model Quest and were applied to support the mineral characterization.

\section{Raman microprobe spectroscopy}

Crystals of ardennite-(As) were placed on a polished metal surface on the stage of an Olympus BHSM microscope, which is equipped with $10 \times, 20 \times$, and $50 \times$ objectives. The microscope is part of a Renishaw 1000 Raman microscope system, which also includes a monochromator, a filter system and a CCD detector (1024 pixels). The Raman spectra were excited by a Spectra-Physics model $127 \mathrm{He}-\mathrm{Ne}$ laser producing highly polarized light at $633 \mathrm{~nm}$ and collected at a nominal resolution of $2 \mathrm{~cm}^{-1}$ and a precision of $\pm 1 \mathrm{~cm}^{-1}$ in the range between 200 and $4000 \mathrm{~cm}^{-1}$. Repeated acquisitions on the crystals using the highest magnification $(50 \times)$ were accumulated to improve the signal to noise ratio of the spectra. Raman Spectra were calibrated using the $520.5 \mathrm{~cm}^{-1}$ line of a silicon wafer. The Raman spectrum of at least 10 crystals was collected to ensure the consistency of the spectra.

A Raman spectrum of ardennite-As is given in the RRUFF data base at http://rruff.info/Ardennite-(As). No assignment of the bands was provided. This spectrum is included in the Supplementary information 2. This RRUFF spectrum does not show bands above $1100 \mathrm{~cm}^{-1}$; no water bands or $\mathrm{OH}$ stretching vibrations are provided when at least the latter could be expected. In the RRUFF spectrum of ardennite-As, some very intense Raman bands are observed between $4000 \mathrm{~cm}^{-1}$ and $5000 \mathrm{~cm}^{-1}$. These bands may be caused by fluorescence.

\section{Infrared spectroscopy}

Infrared spectra were obtained using a Nicolet Nexus 870 FTIR spectrometer with a smart endurance single bounce diamond ATR cell. Spectra over the $4000-525 \mathrm{~cm}^{-1}$ range were obtained by the co-addition of 128 scans with a resolution of $4 \mathrm{~cm}^{-1}$ and a mirror velocity of $0.6329 \mathrm{~cm} / \mathrm{s}$. Spectra were co-added to improve the signal to noise ratio.

Spectral manipulation such as baseline correction/adjustment and smoothing were performed using the Spectracalc software package GRAMS (Galactic Industries Corporation, NH, USA). Band component analysis was undertaken using the Jandel 'Peakfit' software package that enabled the type of fitting function to be selected and allows specific parameters to be fixed or varied accordingly. Band fitting was done using a Lorentzian-Gaussian cross-product function with the minimum number of component bands used for the fitting process. The Gaussian-Lorentzian ratio was maintained at values greater than 0.7 and fitting was undertaken until reproducible results were obtained with squared correlations of $r^{2}$ greater than 0.995 .

\section{Results and discussion}

\section{Mineral characterization}

The SEM image of ardennite-(As) sample studied in this work is shown in Fig. 1. The image shows a crystal fragment up to $1 \mathrm{~mm}$. A perfect cleavage is observed on 010 . Qualitative chemical analysis shows a homogeneous phase, composed by $\mathrm{Si}, \mathrm{Mn}, \mathrm{Al}$ and $\mathrm{As}$. Ca and $\mathrm{V}$ were also observed in partial substitution of $\mathrm{Mn}$ and As, respectively. Semiquantitative chemical analysis shows an As/V ratio equal to $89 / 11$. Zonation of the crystal was not observed and the sample can be considered as a single phase (Fig. 2).

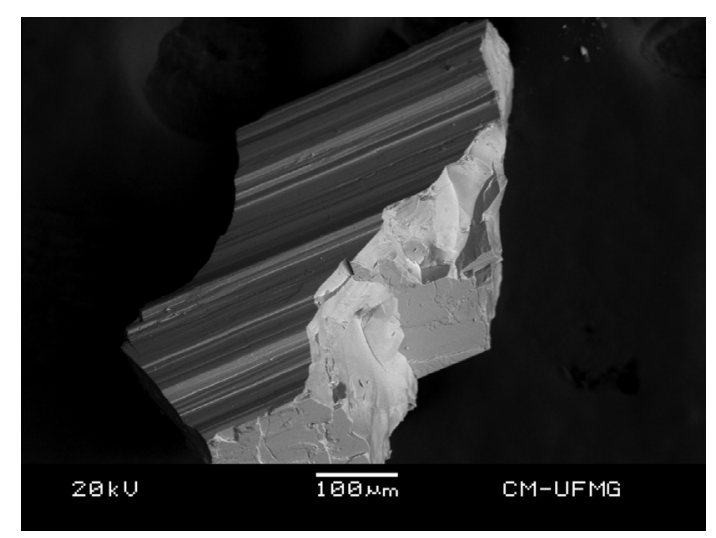

Fig. 1. Backscattered electron image (BSI) of an ardennite-(As) crystal fragment up to $1.0 \mathrm{~mm}$ in length. 


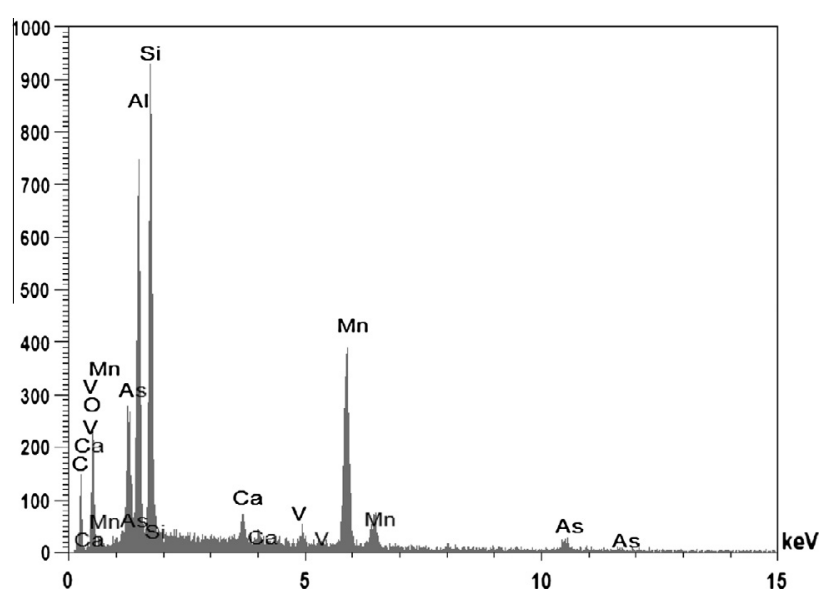

Fig. 2. EDS spectrum of ardennite-(As).

\section{Vibrational spectroscopy}

The Raman spectrum of ardennite-(As) over the $3600-100 \mathrm{~cm}^{-1}$ spectral range is reported in Fig. 3a. This spectrum displays the band positions and relative intensities of these Raman bands. There are large parts of the spectrum where little or no intensity is observed. Therefore, the spectrum is divided into subsections depending upon the type of vibration being studied. It is noted that there is an apparent lack of intensity in the $\mathrm{OH}$ stretching region. The spectrum is dominated by Raman bands in the $1400-1100 \mathrm{~cm}^{-1}$ region. The infrared spectrum of ardennite-(As)
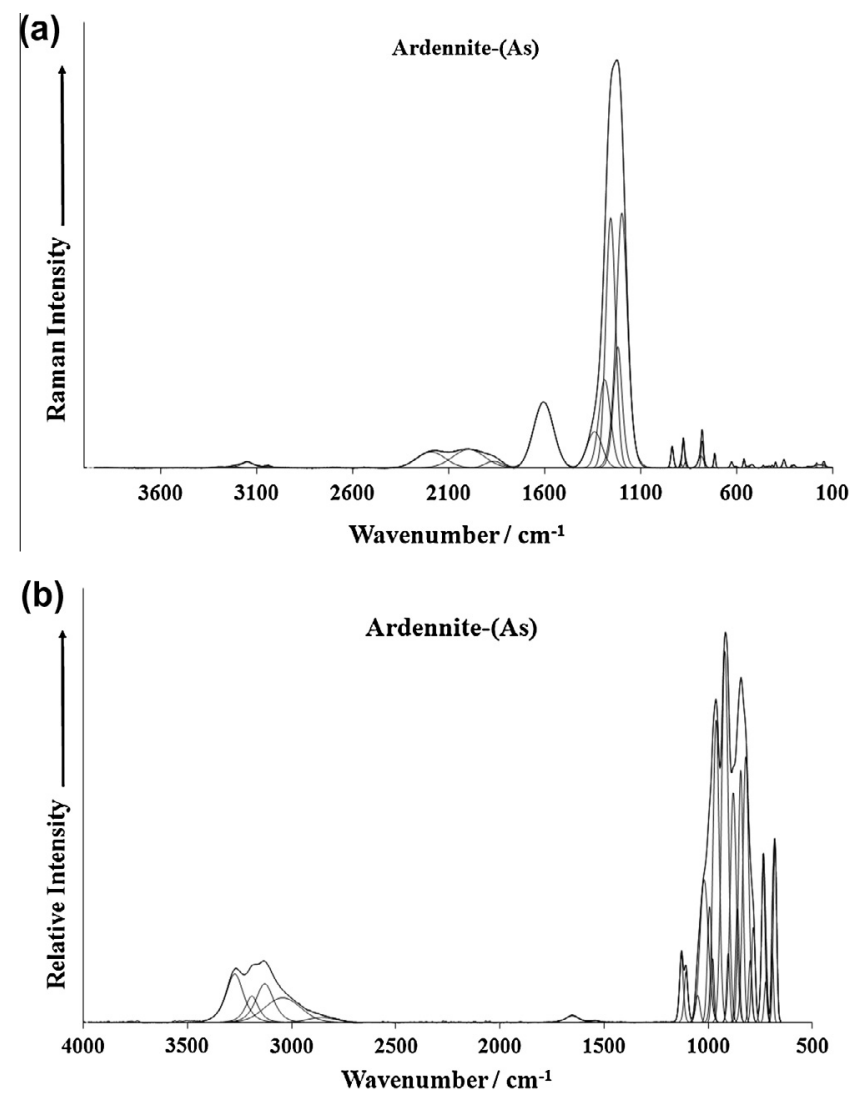

Fig. 3. (a) Raman spectrum of ardennite-(As) over the $4000-100 \mathrm{~cm}^{-1}$ spectral range and (b) infrared spectrum of ardennite-(As) over the $4000-500 \mathrm{~cm}^{-1}$ spectral range. over the $4000-500 \mathrm{~cm}^{-1}$ spectral range is illustrated in Fig. $3 \mathrm{~b}$. The position of the infrared bands and their relative intensities are observed. There are parts of the spectrum where little or no intensity is observed. The infrared spectrum is subdivided into sections based upon the type of vibration being analyzed.

The formula of the mineral ardennite-(As) is $\mathrm{Mn}_{4}^{2+}(\mathrm{Al}, \mathrm{Mg})_{6}$ $\left(\mathrm{Si}_{3} \mathrm{O}_{10}\right)\left(\mathrm{SiO}_{4}\right)_{2}\left(\mathrm{AsO}_{4}, \mathrm{VO}_{4}\right)(\mathrm{OH})_{6}$ and it is expected that there would be Raman and infrared bands dominated by $\mathrm{SiO}_{4}$ and $\mathrm{Si}_{3} \mathrm{O}_{10}$ peaks. The Raman spectrum of ardennite-(As) over the $1100-1800 \mathrm{~cm}^{-1}$ spectral range is shown in Fig. 4a. This spectrum shows strong Raman bands between 1100 and $1400 \mathrm{~cm}^{-1}$ with band components resolved at 1197, 1225, 1287 and $1394 \mathrm{~cm}^{-1}$. These bands are assigned to $\mathrm{SiO}$ antisymmetric stretching vibrations. Because of the complexity of bonded silicate polyhedra, it is difficult to assign the SiO bands.

The Raman band at $1605 \mathrm{~cm}^{-1}$ is due to a water bending mode. Dowty showed that the $-\mathrm{SiO}_{3}$ units had a unique band position of $980 \mathrm{~cm}^{-1}$ [10] (see Figs. 2 and 4 of this reference). Dowty also showed that $\mathrm{Si}_{2} \mathrm{O}_{5}$ units had a Raman peak at around $1100 \mathrm{~cm}^{-1}$. The bands at around $1200 \mathrm{~cm}^{-1}$ are assigned to the SiO stretching vibration of these $\mathrm{Si}_{2} \mathrm{O}_{5}$ units. The infrared spectrum of ardennite(As) over the $1450-1800 \mathrm{~cm}^{-1}$ spectral range is shown in Fig. $4 \mathrm{~b}$. The infrared band at $1650 \mathrm{~cm}^{-1}$ is assigned to the water bending mode of strongly hydrogen bonded water molecules. The observation of bands at $1605 \mathrm{~cm}^{-1}$ (Raman) and $1650 \mathrm{~cm}^{-1}$ (infrared) gives credence to the adsorption of water on the ardennite-(As) surfaces.

The Raman spectrum of ardennite-(As) over the $1000-700 \mathrm{~cm}^{-1}$ spectral range is reported in Fig. 5a. This spectrum shows well-resolved bands with Raman peaks observed at 713, 779, 877 and $935 \mathrm{~cm}^{-1}$. The Raman spectrum of ardennite-As from the (a)

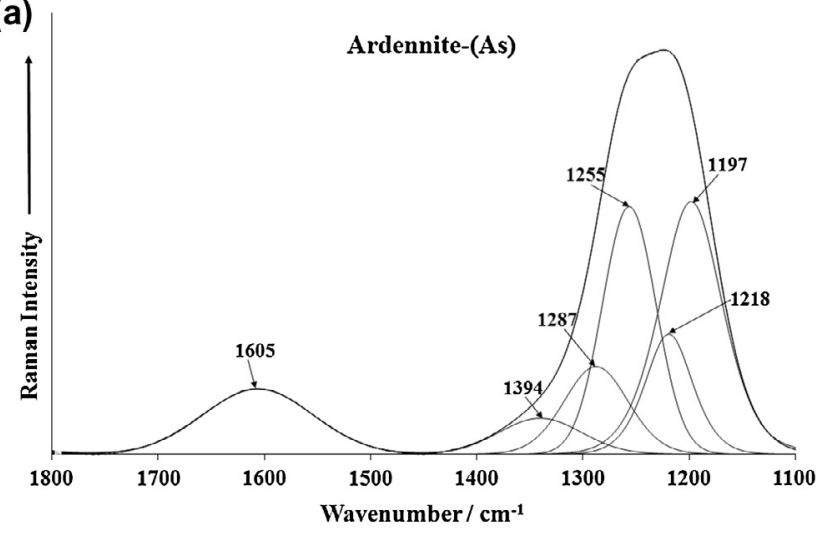

(b)

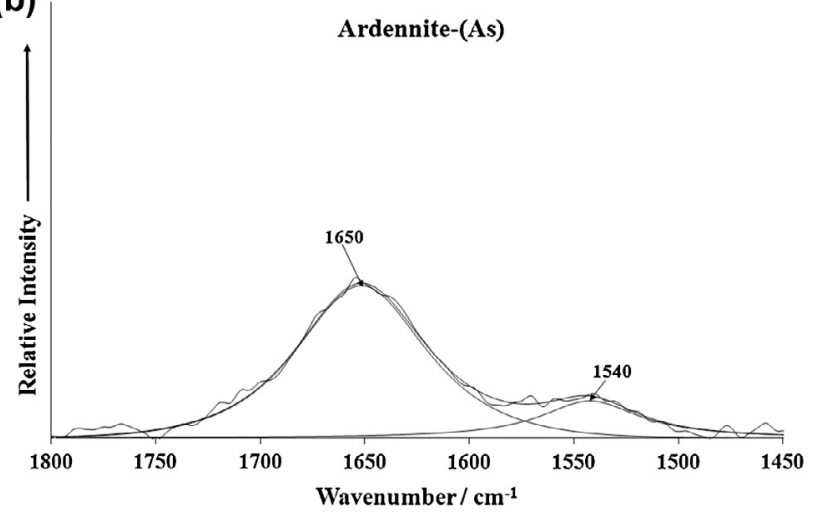

Fig. 4. (a) Raman spectrum of ardennite-(As) over the $1800-1100 \mathrm{~cm}^{-1}$ spectral range and (b) infrared spectrum of ardennite-(As) over the $1800-1450 \mathrm{~cm}^{-1}$ spectral range. 

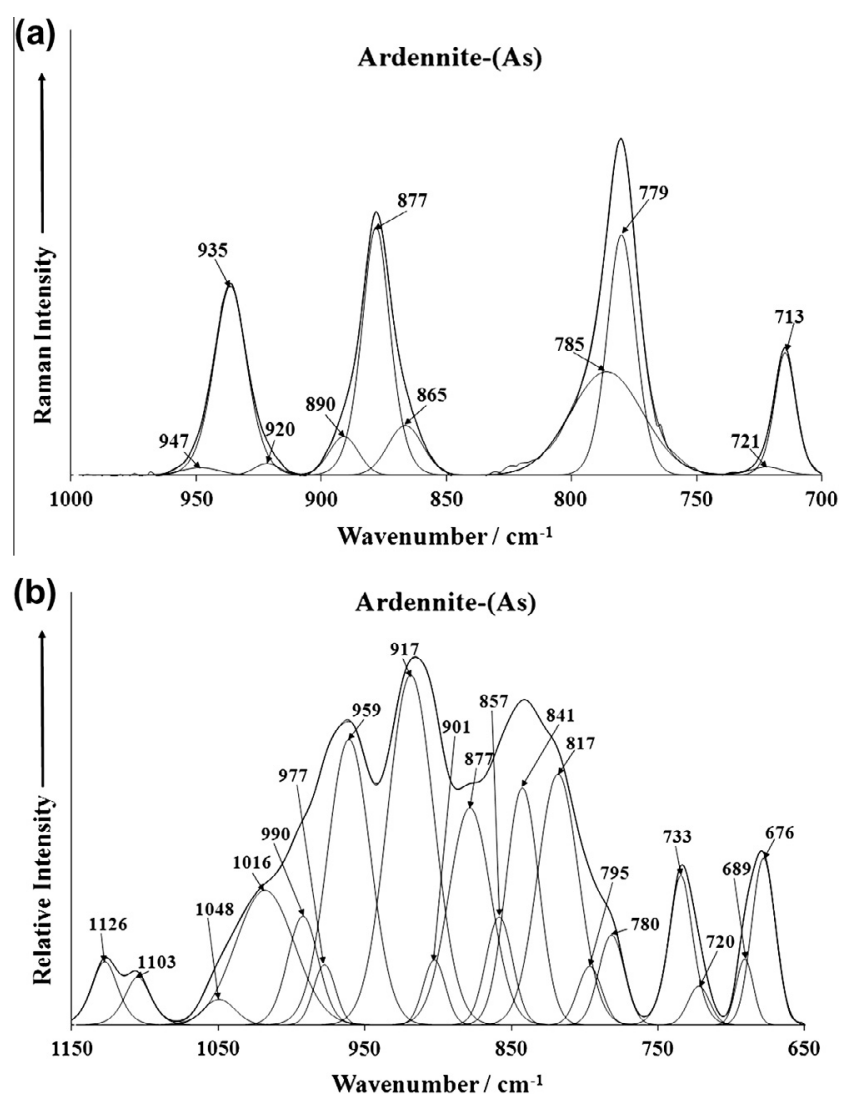

Fig. 5. (a) Raman spectrum of ardennite-(As) over the $1400-800 \mathrm{~cm}^{-1}$ spectral range and (b) infrared spectrum of ardennite-(As) over the $1300-800 \mathrm{~cm}^{-1}$ spectral range.

RRUFF data base (provided in the Supplementary information) shows a very strong peak at $875 \mathrm{~cm}^{-1}$ and two other intense bands at 713,780 and $932 \mathrm{~cm}^{-1}$. The values detailed here are in excellent agreement with our data in Fig. 5a. One possible interpretation of this Raman spectrum is to assign the band at 877 (875 RUFF) $\mathrm{cm}^{-1}$ to the $\mathrm{AsO}_{4}^{3-} v_{1}$ symmetric stretching mode and the band at band at 779 (780 RRUFF) $\mathrm{cm}^{-1}$ to the $\mathrm{AsO}_{4}^{3-} v_{3}$ antisymmetric stretching mode. The semi-quantitative analysis of the ardenniteAs sample shows the ratio of As to $\mathrm{V}$ is about 89/11. The Raman band at 935 (932 RRUFF) is due to the $\mathrm{VO}_{4}^{3-} v_{1}$ symmetric stretching mode. Some low intensity shoulders are also observed. These bands are thought to be related to the $\mathrm{Si}-\mathrm{O}$ stretching and bending vibrations. Dowty calculated the band position of these bending modes for different siloxane units [10]. Dowty demonstrated the band position of the bending modes for $\mathrm{SiO}_{3}$ units at around $650 \mathrm{~cm}^{-1}$. This calculated value is in harmony with the higher wavenumber band observed at $625 \mathrm{~cm}^{-1}\left(628 \mathrm{~cm}^{-1}\right.$ in the RRUFF spectrum).

The infrared spectrum of ardennite-(As) over the $1150-650 \mathrm{~cm}^{-1}$ spectral range is reported in Fig. $5 \mathrm{~b}$. The spectrum shows great complexity with multiple overlapping bands. This complexity shows why the Raman spectroscopy is more advantageous to collect data on ardennite-(As) than infrared spectroscopy. Infrared bands are found at 1103 and $1126 \mathrm{~cm}^{-1}$ and are assigned to the $\mathrm{SiO}$ antisymmetric stretching vibrations. The series of bands observed at 780,817, 841, 877, 901, 917, 959, 977, 990 and $1016 \mathrm{~cm}^{-1}$ are related to the stretching and bending vibrations of the $\mathrm{Si}_{3} \mathrm{O}_{10}$ and $\mathrm{SiO}_{4}$ units. Knowing which band is due to which vibration is difficult to assess.

The Raman spectra of ardennite-(As) in the $650-400 \mathrm{~cm}^{-1}$ and $400-100 \mathrm{~cm}^{-1}$ spectral range are shown in Fig. 6 . There are three (a)

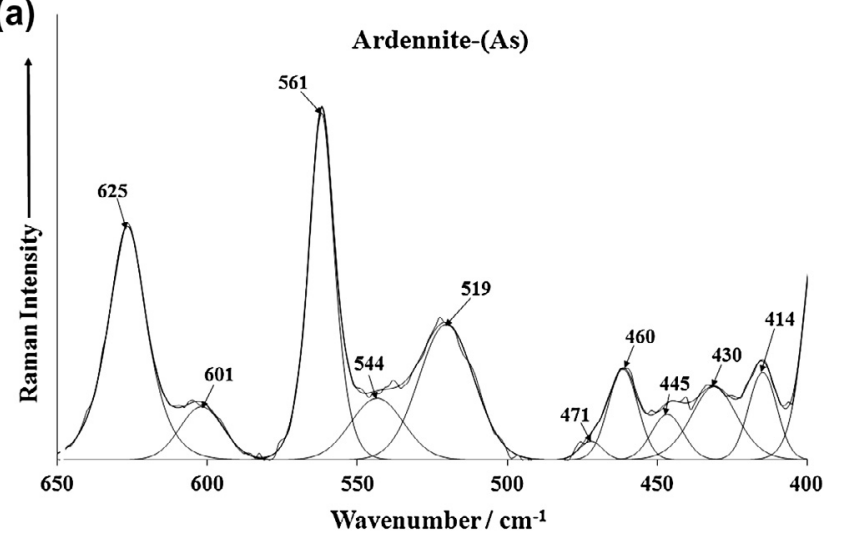

(b)

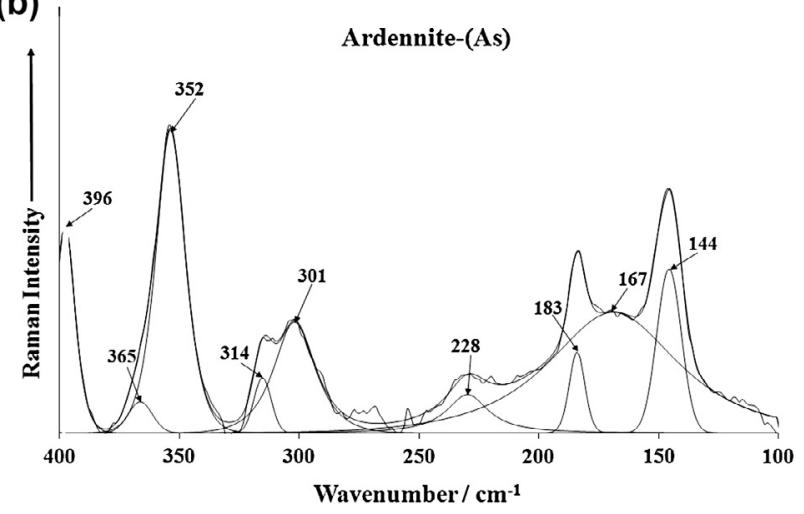

Fig. 6. (a) Raman spectrum of ardennite-(As) over the $800-300 \mathrm{~cm}^{-1}$ spectral range and (b) Raman spectrum of ardennite-(As) over the $300-100 \mathrm{~cm}^{-1}$ spectral range.

sections in the first figure: (a) the bands at 601 and $625 \mathrm{~cm}^{-1}$ (b) the bands at 519,544 and $561 \mathrm{~cm}^{-1}$ (c) the series of bands at $414,430,445,460$ and $471 \mathrm{~cm}^{-1}$. In the RRUFF spectrum of ardennite-(As) Raman bands are observed at 350, 398, 462, 522, 557 and $628 \mathrm{~cm}^{-1}$. The position of these peaks are in harmony with the bands determined in this work as displayed in Fig. 6a. The series of Raman bands between 414 and $471 \mathrm{~cm}^{-1}$ are assigned to the $v_{4}$ out of plane bending modes of the $\mathrm{AsO}_{4}^{3-}$ units. The band at $352 \mathrm{~cm}^{-1}$ (Fig. $6 \mathrm{~b}$ ) is assigned to the $v_{2}$ symmetric bending vibration. Griffith who reported bands at 324 and $310 \mathrm{~cm}^{-1}$ for the bending modes of olivenite.

Dowty calculated the band position of these bending modes for different silicate units [10]. Dowty demonstrated the band position of the bending modes for $\mathrm{SiO}_{3}$ units at around $650 \mathrm{~cm}^{-1}$. Thus, the two bands at 601 and $623 \mathrm{~cm}^{-1}$ are assigned to this vibrational mode. This calculated value is in harmony with the higher wavenumber band observed at $625 \mathrm{~cm}^{-1}$. According to Adams et al. [11] the band at $430 \mathrm{~cm}^{-1}$ is due to the coincidence of both the $\mathrm{B}_{2 \mathrm{~g}}$ and $\mathrm{E}_{\mathrm{g}}$ modes. Thus the series of bands between 414 and $471 \mathrm{~cm}^{-1}$ are due to this bending mode vibration. Intense bands are observed at $301,314,352$ and $396 \mathrm{~cm}^{-1}$. These bands are due to the $\mathrm{MnO}$ stretching and bending vibrations. The other bands in Fig. 5 b at 144,183 and $228 \mathrm{~cm}^{-1}$ are simply described as lattice bands.

The Raman spectrum of ardennite-(As) over the $3400-2900 \mathrm{~cm}^{-1}$ spectral range is illustrated in Fig. 7a. This figure shows resolved bands at $3041,3149,3211$ and $3298 \mathrm{~cm}^{-1}$. The position of these bands is such that they are assigned to water stretching vibrations. The position of these bands suggests that water is strongly hydrogen bonded to the arsenate anions in the ardennite-(As) structure. The formula of the mineral $\mathrm{Mn}_{4}^{2+}(\mathrm{Al}, \mathrm{Mg})_{6}$ $\left(\mathrm{Si}_{3} \mathrm{O}_{10}\right)\left(\mathrm{SiO}_{4}\right)_{2}\left(\mathrm{AsO}_{4}, \mathrm{VO}_{4}\right)(\mathrm{OH})_{6}$ is such that no water is expected in 

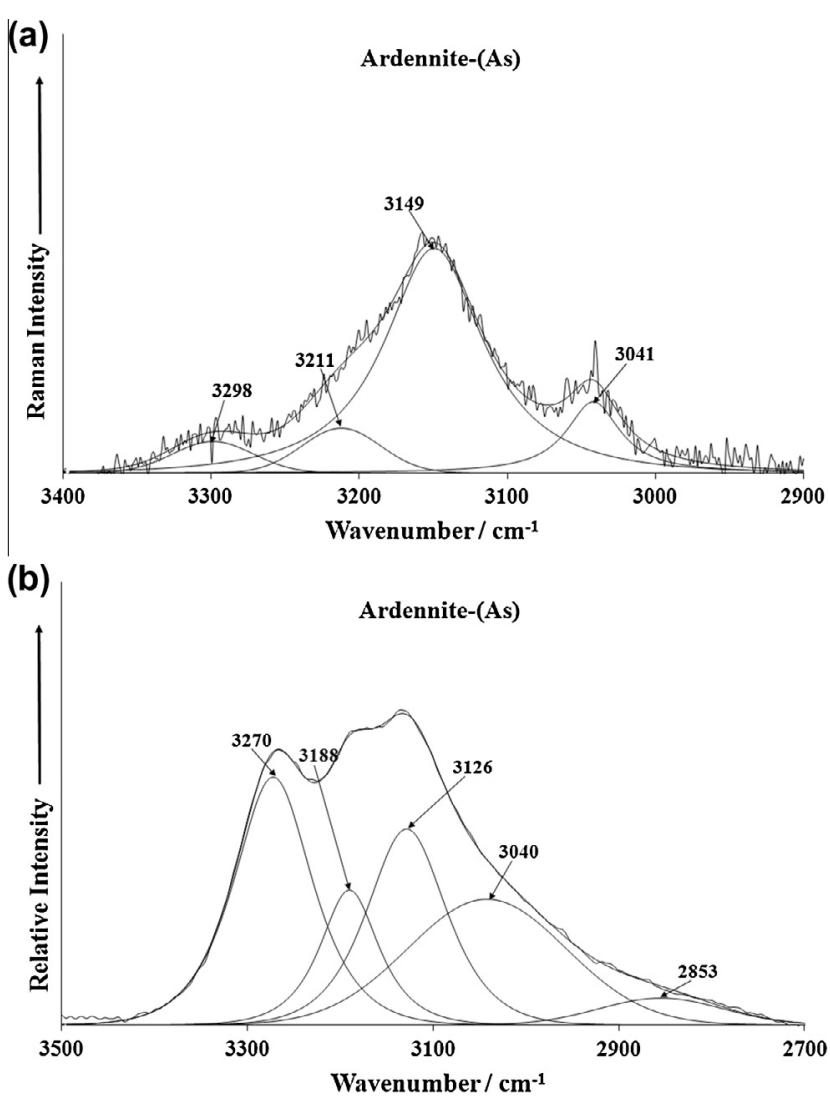

Fig. 7. (a) Raman spectrum of ardennite-(As) over the $4000-2600 \mathrm{~cm}^{-1}$ spectral range and (b) infrared spectrum of ardennite-(As) over the $4000-2600 \mathrm{~cm}^{-1}$ spectral range.

the formula. Thus, if the formula is not correct as it is written, then some water should be expected in the formula of ardennite-(As). Otherwise these bands are due to the $\mathrm{OH}$ units in the ardennite(As) structure. The infrared spectrum of ardennite-(As) in the $1800-1450 \mathrm{~cm}^{-1}$ region, shows a strong band at $1650 \mathrm{~cm}^{-1}$ which is assigned to water bending modes (Fig. $4 \mathrm{~b}$ ). The presence of this band proves that water is adsorbed on the surfaces of ardennite(As). The infrared spectrum of ardennite-(As) in the $3500-2700 \mathrm{~cm}^{-1}$ spectral range is reported in Fig. 7b. Infrared bands are found at 3126,3188 and $3270 \mathrm{~cm}^{-1}$. A broad tail is observed with resolved bands at 2853 and $3040 \mathrm{~cm}^{-1}$. These bands are ascribed to the stretching vibrations of the water units, probably adsorbed on the hydroxyl surface of ardennite-As. These bands are assigned to the stretching vibrations of the $\mathrm{OH}$ units.

Both Raman and infrared bands in the $\mathrm{OH}$ stretching region, indicate the presence of water on the surface of ardennite-(As). However, the accepted formula has only $\mathrm{OH}$ units; thus bringing into question the formula of ardennite-(As). The formula of the mineral is given as $\mathrm{Mn}_{4}^{2+}(\mathrm{Al}, \mathrm{Mg})_{6}\left(\mathrm{Si}_{3} \mathrm{O}_{10}\right)\left(\mathrm{SiO}_{4}\right)_{2}\left(\mathrm{AsO}_{4}, \mathrm{VO}_{4}\right)(\mathrm{OH})_{6}$.
However, the bands which could be assigned to $\mathrm{OH}$ stretching or deformation modes could be identified.

\section{Conclusions}

A study of the rare mineral ardennite-(As) was made using a combination of SEM with EDX and infrared and Raman spectroscopy. Qualitative chemical analysis shows a homogeneous phase, composed by $\mathrm{Si}, \mathrm{Mn}, \mathrm{Al}$ and As. Some minor substitution of $\mathrm{V}$ for As and $\mathrm{Ca}$ for Mn was observed. Raman bands were assigned to the stretching vibrations of the siloxane and arsenate units. Both Raman and infrared bands in the $\mathrm{OH}$ stretching region, indicate the presence of water in the structure of ardennite-(As). However, the accepted formula has only $\mathrm{OH}$ units; thus bringing into question the formula of ardennite-(As). The formula of the mineral is given as $\mathrm{Mn}_{4}^{2+}(\mathrm{Al}, \mathrm{Mg})_{6}\left(\mathrm{Si}_{3} \mathrm{O}_{10}\right)\left(\mathrm{SiO}_{4}\right)_{2}\left(\mathrm{AsO}_{4}, \mathrm{VO}_{4}\right)(\mathrm{OH})_{6}$. The position of the $\mathrm{OH}$ stretching vibrations provides strong evidence for bonding of water to the hydroxyl surfaces of ardennite-(As). Vibrational spectroscopy offers new information on the molecular structure of ardennite-(As) which might not be readily obtained by other methods.

\section{Acknowledgements}

The financial and infra-structure support of the Discipline of Nanotechnology and Molecular Science, Science and Engineering Faculty of the Queensland University of Technology, is gratefully acknowledged. The Australian Research Council (ARC) is thanked for funding the instrumentation. The authors would like to acknowledge the Center of Microscopy at the Universidade Federal de Minas Gerais (http://www.microscopia.ufmg.br) for providing the equipment and technical support for experiments involving electron microscopy. R. Scholz thanks to CNPq - Conselho Nacional de Desenvolvimento Científico e Tecnológico (Grant No. 306287/ 2012-9).

\section{Appendix A. Supplementary material}

Supplementary data associated with this article can be found, in the online version, at http://dx.doi.org/10.1016/j.saa.2013.09.148.

\section{References}

[1] A.A. Barresi, P. Orlandi, M. Pasero, Euro. J. Mineral. 19 (2007) 581-587.

[2] C. Chopin, Bull. Min. 101 (1978) 514-531.

[3] D.S. Coombs, Y. Kawachi, A. Reay, Min. Petr. 48 (1993) 295-308.

[4] T. Minakawa, H. Momoi, Kobut. Zasshi 18 (1987) 87-98.

[5] N. Sasaki, M. Yano, F. Matsuyama, Chig. Kenkyu 51 (2002) 67-72.

[6] P.B. Moore, Can. Min. 8 (1965) 262-265.

[7] P.B. Moore, J. Shen, T. Araki, Amer. Min. 70 (1985) 171-181.

[8] M. Pasero, T. Reinecke, A.M. Fransolet, Neues Jahrb. Min. Mh. 166 (1994) 137-167.

[9] G. Donnay, R. Allmann, Acta Cryst. B24 (1968) 845-855.

[10] E. Dowty, Phys. Chem., Min. 14 (1987) 80-93.

[11] D.M. Adams, R.S. Armstrong, S.P. Best, Inorg. Chem. 20 (1981) 1771-1776. 